Open Access

\title{
Do calculus students demand technology integration into learning environment? case of instructional differences
}

\author{
Eyüp Sevimli
}

Correspondence: eyup.sevimli@gop.edu.tr

Faculty of Education,

Gaziosmanpaşa University, 60150

Tokat, Turkey

\begin{abstract}
This study evaluated how calculus students' attitudes towards usage of technology changes according to their learning environment and thinking types at the undergraduate level. Thus, the study attempted to determine the place and importance of technological support in the process of attaining the aimed and obtained acquisitions by students. Participants of the study consist of forty-three calculus students who are studying in traditional or CAS-supported teaching environments, and have different thinking types. Pre-and post-assessment tools were used in the data gathering process, and the data were evaluated with descriptive statistics. The results of the study showed that students in the traditional group place more importance on procedural skills, while students in the CAS group attach more importance to conceptual skills in terms of instructional objects. It also determined that acquisitions, which students think developed differ according to learning environment and thinking types. The main implications of the study were discussed in terms of the related literature and teaching practice.
\end{abstract}

Keywords: Technology, Higher Education, Calculus, Thinking Types

\section{Introduction}

Regardless of the fact that it has been more than 30 years since the introduction of technology into mathematics classes, debates relating to the role and effectiveness of technology in the teaching-learning process are continuing without slowing down. Debates gained a new dimension, especially with the increase of computer software programs, graphing calculator interface, and learning objects (e.g., graphing, numerical algorithms, calculations, modelling) which were developed for certain instructional objectives; technology's compatibility with a student, concept, and teacher objectives was also studied. According to Tall et al. (2008), of all the areas in undergraduate mathematics, calculus has received the most interest and investment in the use of technology with an increased number of innovative approaches. The fact that technology's integration into calculus is prioritized by research and software developers can be explained in two ways: Since calculus is not just a part of mathematics, it is also a core curriculum in engineering, science, and some social science departments, it creates a bigger market for software developers; more than half of the students taking the course fail and students who have difficulty in traditional environments are the main factors that

(c) 2016 The Author(s). Open Access This article is distributed under the terms of the Creative Commons Attribution 4.0 International License (http://creativecommons.org/licenses/by/4.0/), which permits unrestricted use, distribution, and reproduction in any medium, provided you give appropriate credit to the original author(s) and the source, provide a link to the Creative Commons license, and indicate if changes were made. 
direct researchers to search for alternative and innovative teaching-learning approaches (Tokpah 2008). The pioneers of the "calculus reform movement" known as the Harvard Calculus Consortium defended the necessity of conceptual understanding against procedural understanding; for this reason, they suggested that instructional context should be enhanced with multiple representations and should be supported with technology (Hughes-Hallett 1991; Vlachos \& Kehagias, 2000). However, despite all of the developed sophisticated instruments and alternative teaching approaches in calculus, the number of lecturers who integrated technology into the learning process remained limited (Marshall et al. 2012). While instructional technology is greeted more warmly in the departments that use mathematics as a tool, in the mathematics departments there are still prejudices against the usage of such technologies. Even though some of the lecturers stated that they are optimistic about mathematical software, the general opinion leans towards the idea that the use of technology in mathematics teaching will weaken the basic skills required for advanced mathematics (Nabb, 2010). Another situation which is worth mentioning at this point is the students' demands and attitudes towards technology. Although there is a large amount of research in literature which includes usage of technology in mathematics classrooms, especially calculus classrooms, the effectiveness of these studies is limited because the expectations and demands of students are not taken into account (Marshall et al. 2012; Samuels, 2010; Swidan \& Yerushalmy, 2014). In other words, nowadays, while technology has been trying to find its place in learning environments, there is a shortage of research in literature that considers the needs of the students who are basic components of didactic environments. In this study, opinions of calculus students about technology integration into learning environments were discussed within the context of teaching environments and thinking type differences. For this purpose, answers were sought for the research question below: "How do the calculus students' attitudes towards technology change regarding the following variables: teaching environments and thinking type differences?" Thus, the effect and role of technology in the process of attaining the goals and acquisitions of the course are brought forth. Besides, this study is important because it brings a new perspective on how the need for technology is shaped according to instructional differences.

\section{Theoretical framework}

The researchers have placed particular importance on undergraduate mathematics and especially the issue of technology integration in calculus compared to the other teaching levels and disciplines (Marshall et al. 2012; Rasmussen et al. 2014; Tall et al. 2008). A macro-framework for understanding the place of technology in the teaching and learning of calculus has been prepared by Rotman (1995) to evaluate the students' mathematical reasoning (cited in Meagher, 2011). According to this framework, subject, agent, and person are three core elements for integrating technology into the classroom environment. The effectiveness of the teaching-learning process is measured by the strength of the ties between these three components. In his technology integration model which was specially used in calculus, Meagher (2011) changed these three components to be calculus, CAS, and students. As shown in Fig. 1, in the designed technology-supported learning environment, necessities and differences of individuals 


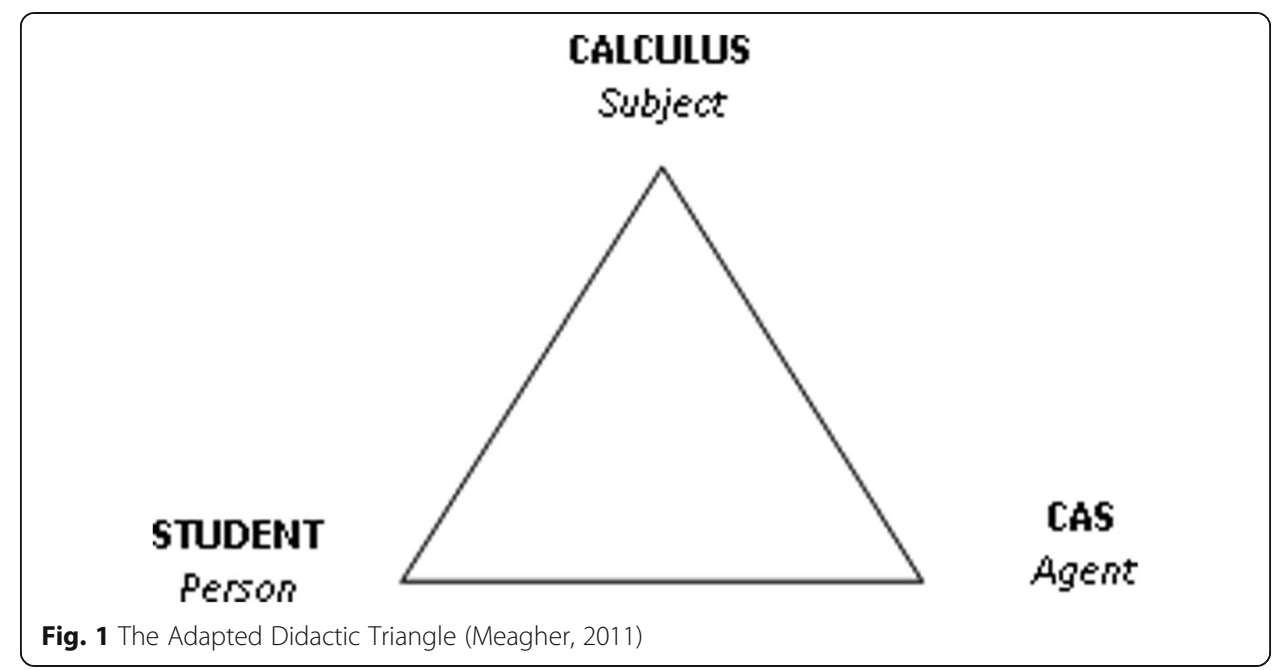

(person) should be taken into consideration. Some of those individuals are lecturers, and lecturers teaching paradigms also shape expectations of students.

There are several studies in literature that explain the interaction between teacher and technology on the basis of the pedagogical content knowledge and course objectives (Cavin, 2007; Kendal, 2002; Marshall et al. 2012; Tokpah, 2008). Kendal (2002) mentions that technology-supported teaching carried out by a lecturer who lacks technological content knowledge will not yield the expected results. Another reason why lecturers' remain distant from the usage of technology is related to the objectives of the course and to the limited interactive activities of the software. Furthermore; epistemological beliefs between traditionalists and reformist mathematicians can also affect the use of technology at the undergraduate level (Tokpah, 2008). Hung (2001) discusses lecturers' opinions on the basis of philosophical approaches to mathematical teaching while stating that traditionalist mathematicians are less likely to use technology; he also observed that lecturers who prefer technology are more likely to choose software that emphasizes the importance of drill-and-practice (cited in Tokpah, 2008). The calculus reform movement is one of the reformist approaches which points out that knowledge in calculus courses should be learned by students conceptually. But, some mathematicians think that technology-supported reformist-teaching approaches harm the nature of mathematics and simplify the mathematical content (Wilson, 1997). They claim that while some textbooks which were restructured according to the calculus reform movement emphasized the use of technology, mathematical realities are ignored (Chappell \& Kilpatrick, 2003). However, Quesada et al. (2008) found that use of graphical teaching via the graphing calculator aids not only visual reasoning but also student understanding of the formal definition in calculus. The discussion about the calculus reform movement and thus the place of technology in calculus classes is ongoing.

\section{The use of CAS in teaching and learning of calculus}

Three types of instructional technologies are seen more frequently in undergraduate level mathematics. These are graphing calculators, a Computer Algebra System (CAS), 
and Dynamic Geometry Software. However, the most practical instructional technology among them is the CAS (Vlachos \& Kehagias, 2000). Since each CAS has interfaces that can execute algebraic calculus operations such as derivative, integral, matrix, and determinant, they can be regarded as a kind of calculating machine that provides convenience for mathematicians. At the same time, a CAS is an effective visualization tool with menus providing different projections like plotting 2-D or 3-D graphs (Brown \& Steele, 2014; Swidan \& Yerushalmy, 2014). The technology-supported teaching environments, as enhanced by the use of a CAS, can help connect symbolic and visual representations of mathematical concepts so that students can utilize from the visual or analytic reasoning in the problem-solving process (Nishizawa et al. 2014; Sevimli, 2013). The findings obtained from a literature review (of 326 papers) regarding the purpose of CAS usage, showed that CAS tools were most widely used for experimentation (63\%) and visualization (59\%) in tertiary mathematics education (Buteau et al. 2010). Vincent et al. (2010) claim that the web based-platforms such as Wolfram|Alpha are more useful than a standard CAS software because of their advantages such as natural language processing always being up-to-date, and the "show details" feature. However, simply bringing the software into the teaching environment does not mean that the teaching is now technology assisted. Teachers' technological content knowledge and students' expectations must be taken into consideration. For instance, the study carried out by Eichler and Erens (2014) showed that only a few teachers (2 out of 29) integrate technology into their intended curricula in a sophisticated way to improve students' understanding, whereas most of the teachers used to reduce students' investment in calculations. It is unclear how much CAS-supported teaching is able to fulfil the expectations of students and how these expectations change according to individual differences. It is important to determine the expectations of students and examine whether or not the capacities of technological tools meet these expectations. However, there are very few studies in the literature which can be related to this topic. Several studies show that one of the differences that could help determine priorities of calculus students is a mathematical way of thinking (Haciomeroglu et al. 2010; Presmeg, 1985).

\section{Students thinking differences in calculus}

Mathematical thinking should not be regarded as a kind of mathematical skill; it should be regarded as a preference of how mathematical skills are used (Borromeo-Ferri, 2010). Poincare (1900/1907), while pointing out the thinking process in the nature of mathematics, stated that students and mathematicians have two different minds which are "logical" and "intuitive" and these minds refer to the these two types of thinkers as geometers and analysts, respectively (cited in Galindo-Morales, 1994). Presmeg (1985) associated mathematical ways of thinking with the usage of visualization when attempting to solve mathematical problems and she distinguished students as visualizers and non-visualizers. Visualizers are individuals who prefer to use visual methods like drawing graphs, using diagrams or depicting the spatial information when attempting mathematical problems and non-visualizers are individuals who prefer not to use visual methods when attempting such problems. The nature of calculus also frequently requires the use of both these methods. In many studies in calculus, individuals who use non-visual solution methods are referred to analytical thinkers (Borromeo-Ferri, 2010; 
Sevimli, 2013). Lean and Clements (1981) found that the problem- solving success of analytical thinkers is relatively higher than visual thinkers. On the other hand, Lowrie and Kay (2011) observed that when students apply visual strategies to understand the data in problems that they found complex, they tend to use the analytical strategies in easier problem types. It is also known that students make more effort by managing the visual processes than the analytical processes (Presmeg, 2006). Many of the researchers studying students' thinking differences in Calculus have stated that the teaching environment must be structured by supporting the different thinking strategies for conceptual understanding (Galindo-Morales, 1994; Sevimli, 2013). Students with different types of thinking benefit differently from traditional and CAS-supported learning environments (Galindo-Morales, 1994). For instance, Sevimli (2013) found that visual students benefit more from the opportunities of a CAS-supported classroom than the other thinkers in the classroom in terms of transitioning between different representations of a concept. Literature findings outlined above prompted researchers to investigate how demands of students which are related to technology change according to learning environments.

\section{Methods}

This study is a part of a long-term, large-scale project, which includes research designs such as pre-field research and teaching experiments in its background. The aim of the study was to maximize information and critical cases (diversity) when examining calculus students' technology demands, not to facilitate generalization (Haciomeroglu et al. 2010; Lincoln \& Guba, 1985). Thus, the embedded case study method, one of the qualitative designs, was used in the study.

\section{Research group}

The research group of this study consists of forty-three freshmen students who are studying mathematics in the science faculties of a university in Turkey. The university in which the study was conducted is one of Turkey's leading educational institutions with more than 65,000 students, and calculus is taught in the mathematics department and alongside many science and engineering departments. Students in the research group took Calculus-I before the implementation and this study were conducted under Calculus-II course. The research group has different characteristics according to the teaching environment. Two teaching environments have been created as part of the study, which are traditional and CAS-supported teaching environments. In this study, thinking types of students were also taken into account in order to diversify differences in learning environments. Details of the thinking types are explained under the "data collection" sub-heading.

\section{Setting}

Students in the study group were randomly assigned to traditional (25 students) or CAS (18 students) groups and teaching processes lasted for six weeks. Since the legal permission given by the institution foresees that the study will be completed in six weeks, the study has been conducted for six hours each week for a total of $36 \mathrm{~h}(6 \times 6=36)$. 


\section{Traditional environment}

At the first researchers tried to understand the nature of the teaching environment in a traditional calculus classroom with pre-field research which he conducted by using observation and content analysis techniques. The findings of this research are: a) Calculus-I, which was given to students studying mathematics in the fall semester, was taught by a mathematics professor by following traditional textbooks; $b$ ) Symbolic language and algebraic representations were predominantly used in lectures; $c$ ) It was observed that students often tried to write down the lecture notes on the board; $d$ ) Lectures are taught using the expository teaching approach and question-answer techniques. In light of the information above, there was no interference in traditional group lectures and the same instructor continued to give lectures.

\section{CAS-supported environment}

In this study, the concept of "integration technology into the teaching environment" is limited with the CAS-supported teaching process. While designing the CAS-supported teaching environment, Meagher's (2011) model containing phases of technology integration into teaching environments are taken into consideration. In this context, first of all it should be explained for what purpose technology is going to be used in teaching environments. Since Calculus-II is a course which has theoretical and applied content received in the mathematics department, CAS-supported teaching processes are followed, not CAS-based. The CAS was used as a tool for creating, viewing and/or modifying graphical renderings of mathematical objects to enhance conceptual discussions and support visualizations (Buteau et al. 2010). In the theoretical parts of lectures, a CAS software program was used limitedly to visualize some proofs and to discover different meanings of a concept. While there is a large number of instructional software which can be used in calculus courses, some of the software functions that simplify calculation operations of engineering departments are predominant, and in others visualization tools are limited and software language is complex (Sevimli, 2013). In the LiveMath study, (previously known as Theorist), a CAS software program was preferred because of "a unique user interface that allows one to perform 'natural' algebraic manoeuvres even more 'naturally' than one can achieve them on paper" (Kaput, 1992; p.534). This software also allows the students to perform symbolic manipulation, to drag-spin in the 3-D graph, to use easy syntax and interactive animation). The computerized learning environment has included the interactive LiveMath activities which encourage the students in the context of visualization, translating between representations and making contact between disciplines. Figure 2 includes an example based on graphical and numeric calculations with which students can answer with the Limits of Riemann Sums.

Technology is used in the group following a CAS-supported teaching process according to the operation steps below: a) The learning process in the CAS group was conducted by a mathematics lecturer who has technological-pedagogical content knowledge and has years of experience in teaching calculus; $b$ ) Before the implementation, the features of the software were introduced to the CAS group to ensure that students are accustomed to technology-supported environment; c) The theoretical part of the course was given in a lecture hall and additionally, CAS content which supports visual reasoning in related topics were included; $d$ ) The practical part of the course was given in computer lab and active participation of students in the usage of technology 


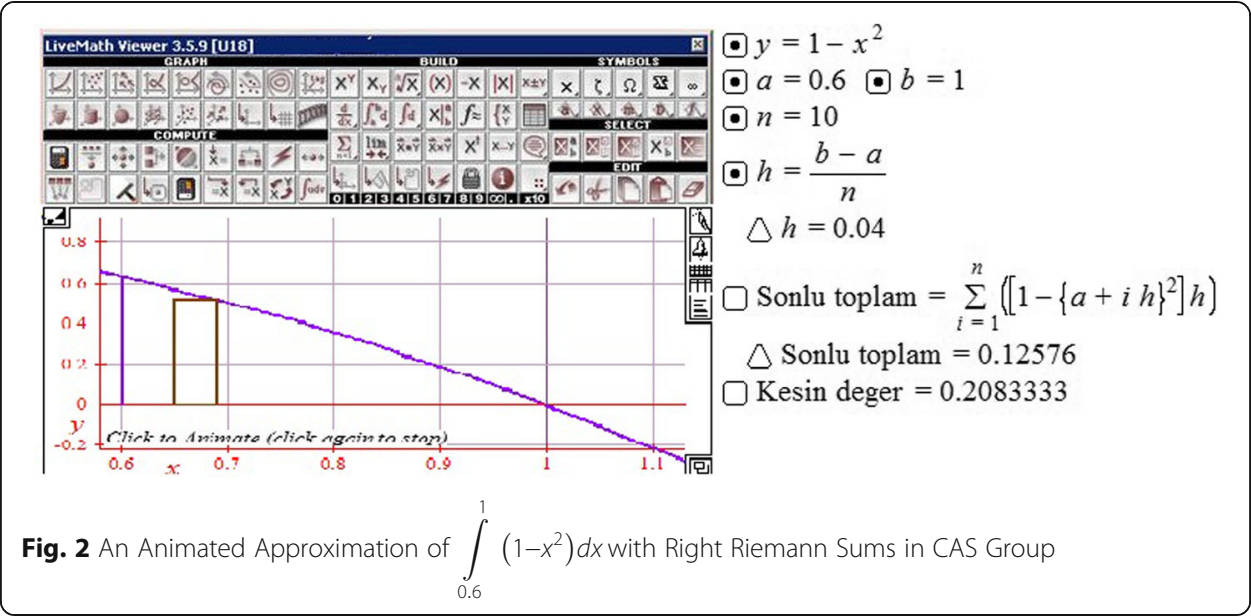

was supported with an activity-based approach, e) In contrast to traditional groups, technology support is used to present different representations related to problem situations in the CAS group.

\section{Data collection and analysis process}

Three types of data collecting tools were used in the study consisting of tests, questionnaires, and interviews. Tests are auxiliary instruments which are used in order to determine differences in a teaching environment before implementation. The main data is collected by questionnaires and interviews, and after administering the questionnaire, semi-structured interviews were conducted with four respondents for a deeper understanding of the views on integration technology into calculus. The data collection process is summarized in Fig. 3. Information about the process of data analysis, which

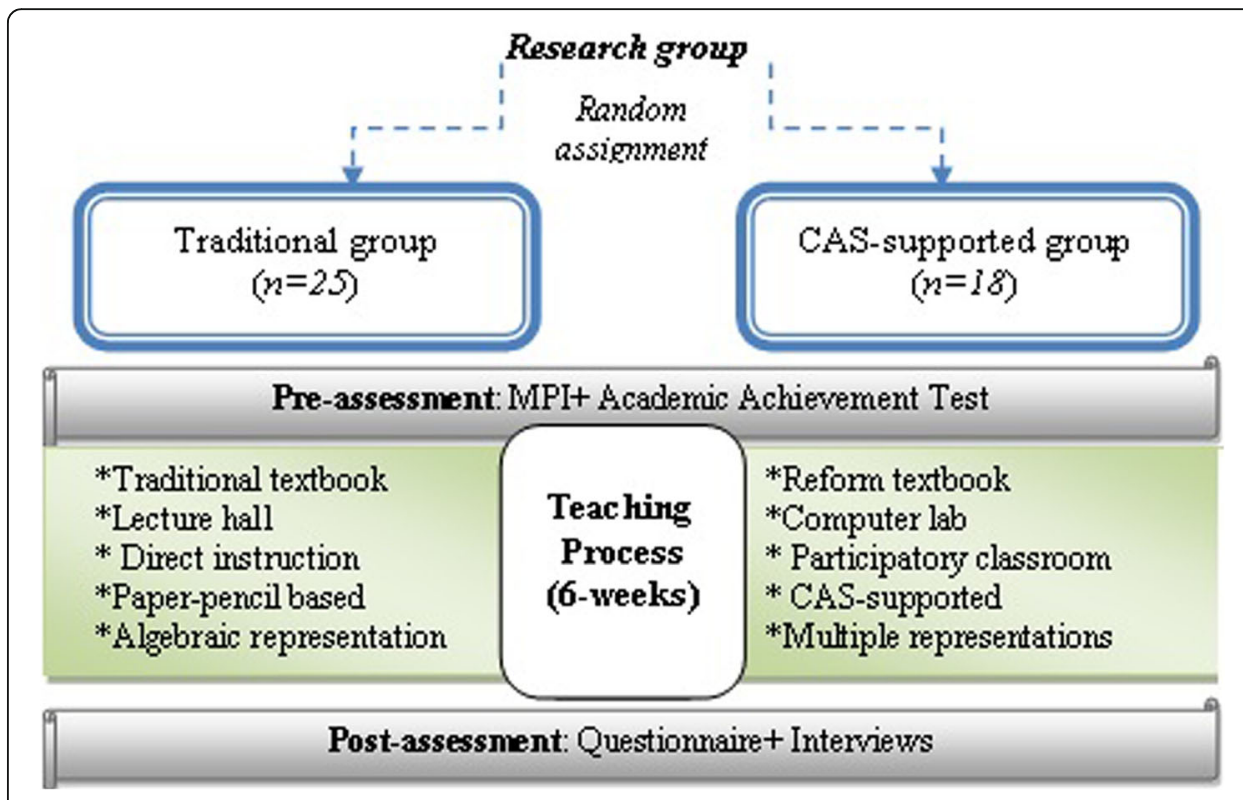

Fig. 3 Flow Chart of Data Collection Process 
is gathered under the titles of "pre-assessment" and "post-assessment" are shared below.

\section{Pre-assessment}

The tests used before implementations are an academic achievement test and an MPI. An academic achievement test consisting of the subjects of Calculus-I was conducted before the implementation in order to determine whether study groups were equal or not. The achievement test contained multiple choice questions on subjects such as limit, continuity, and differentiation, which were all evaluated on a scale of 100 . The test findings revealed that students in the traditional group and the CAS group showed similar performances before the implementation process and no statistically significant differences among the groups were found for academic achievement $\left(\bar{X}_{\mathrm{Tra}}=68.5, \bar{X}\right.$ CAS $=66.9, S d=41, t=-0.04, p=0.94$ ).

Another test which was used before implementation was The Mathematical Process Instrument (MPI). The instrument was used to categorize the participants as analytical or visual according to their mathematical thinking types. MPI was developed by Suwarsono (1982), and Presmeg (1985) modified this instrument to be used at higher education level. As the participants of this study were university students, the modified version of MPI was preferred in the study, which had a total of 18 questions. Each problem in the MPI could be solved using either visual or non-visual methods. For the analysis of MPI scores, Presmeg's (1985) analysis framework was used. Regardless of whether the answer was correct or incorrect, each visual solution received 2 points and each non-visual solution received 0 . Therefore, each participant had a total score between 0 and 36. Thus the ones who had points between 0-12 were coded and categorized as participants who use analytical thinking (preferences of non-visual methods) and the ones who had points between 22-36 were coded and categorized as participants who use visual thinking (preferences of visual methods).

\section{Post-assessment}

After the implementation, a questionnaire was used to evaluate the learning outcomes. The questionnaire used in this study has been developed based on the results of a pilot study and has been formed with the categorization of frequently encountered answers. In the pilot study, students were asked to write an answer to the questions "what should be the instructional objectives of calculus, which objectives do you expect is going to develop with the course?" and that "what are the competencies that you think you have developed end of the teaching process?" For example, the indicator words in the written answers such as finding integral, knowing the rules of derivate or solving algebraic equations were labelled and categorized under "procedural flexibility". The findings of a pilot study have shown that instructional objectives can be analyzed under five categories, while acquisitions obtained end of course can be analyzed under six categories. The categorized data were presented with a table under the two themes: expected instructional objectives and obtained acquisitions. While forming categories related to objectives and acquisitions in calculus, opinions of mathematics professors were consulted who teach this course for a long time. In addition to the researcher classification, each answer was coded individually by two different coders to achieve reliable categorization. When the agreement was not initially achieved, differences were discussed and the final code was agreed upon with a common classification. High 
compliances were achieved between second coders and researchers in the classification process. In the questionnaire, which is carried out after the implementation process, students are asked to select one or more of the categories and explain why these categories were specially selected. The categories given in the questionnaire are: instructional objectives and acquisitions that the students aimed to achieve during the course. A formal definition of the each category was presented in the questionnaire to ensure that different participants interpreted a category in a similar manner. The students are also encouraged to write (if there is any) different objective and acquisition except those categories. Quotes from the students' written answers were also included for each topic as proof of an argument.

The interviews have been used to evaluate how the outputs of the teaching process change according to thinking types. Semi-structured interviews were conducted with the four selected students and were audio recorded. Describing who will be selected for the interview and the principles that affect the selection will make it easy to interpret the findings. Considering the fact that along with types of thinking, differences in teaching environments might also affect the demands of students regarding technology; students who have sufficied to represent these differences were chosen. For this reason, participants in the interviews were selected using a purposeful sampling technique from voluntary students. The main selection criteria were that each participant had a different thinking type in each environment (CAS or Traditional). Interviews were conducted with visual and analytical thinkers (contrasting cases) in order to determine the similarities and differences between the technological demands of students (Haciomeroglu et al. 2010). Participants were coded with a formulization in the form of environment and thinking types. Analytic participants who are in traditional and CASsupported environments were coded with Tra-A and CAS-A, respectively. Also, Tra-V and CAS-V codes were used to define visual participants who are in traditional and CAS-supported environments. MPI points (out of 36) of the participants are shown below: CAS-A was 7, CAS-V was 25, Tra-A was 5 and Tra-V was 22. Each participant's interview lasted approximately $40 \mathrm{~min}$, and each of them was transcribed. During interviews, participants were asked to explain their attitudes towards the usage of CAS in calculus considering their expectations of the course. Interview data were analyzed with an open coding method, which consists of identifying, naming, categorizing, and describing phenomena found in the text for the thematic analysis (Strauss \& Corbin, 1998). During the open coding process, semi-structured interview data were transcribed, and responses to the same interview questions of the participants who had different thinking types and settings were coded in terms of previously identified categories. The findings obtained by usage of frequently-repeated objectives and acquisitions in the interviews were summarized in the table (Table 2). Some selected quotes (for each participant) were also shared in the text to be able to characterize the participants' attitudes towards usage of CAS.

\section{Findings}

The findings of the study were presented in two steps. First of all, general findings were presented in terms of acquisitions, which were thought to be aimed and obtained by calculus students with respect to setting differences. Afterwards, the role of thinking 
types was particularly taken into consideration while evaluating the attitudes towards CAS integration into calculus.

\section{Objectives and acquisitions of the calculus}

In the findings of the questionnaire gathered under this title, students were asked to explain the knowledge or skills they aimed to achieve at the end of the course. The findings of the questionnaire that were analyzed according to their content showed that instructional objectives which are associated with calculus could be gathered under four categories (Table 1). Procedural flexibility, among one of the categories was the most associated instructional objective with calculus by students. When findings are interpreted with respect to variables of teaching environment by taking into account the clustering remarks, it can be seen that students in the CAS group consider "conceptual understanding" and students in traditional group consider "procedural flexibility" more important. While students in the CAS group also take "interdisciplinary relation" into account, $40 \%$ of the students in traditional group also stated that they were aiming to improve their "abstract thinking" after the calculus course. Direct quotations of some of the interview contents supporting this implication are presented below. Emphasis was placed on procedural and conceptual skills by one participant from each group (CAS and traditional) as seen in the quotations.

Students in traditional group: It is important to be able to do derivative or integral operations quickly and correctly, the primary objectives of the course could be, knowing how to use rules and technique.

Students in CAS group: Unlike in high school, it is required to interpret different meanings of a new mathematical concept at the university level. For example, rates of change of derivatives are more important than finding a derivative.

Another aim of the questionnaire is to evaluate the implemented teaching processes from the student's perspective. In this context, students in the CAS group and students in the traditional group evaluated CAS-supported teaching process and traditional teaching process in terms of learning outcomes, respectively. Findings indicated that students developed themselves in five mathematical acquisitions. The most apparent of them are "algebraic thinking" and "computation", which students think they achieved at the end of the calculus course (Table 1).

The findings of the questionnaire showed that acquisitions, which students think developed differ according to types of teaching environments. While acquisitions, which were pointed out by students in the CAS group, but never mentioned in traditional group are "using representations", the only acquisitions pointed out in the traditional group but never mentioned in the CAS group are "proving theorems". Two explanations in the questionnaire which were evaluated within the categories of "using representations" and "proving theorems" separately are shared below.

Students in traditional group: We run the course on the basis of definition-theorem and proof. I thought I was going to deal with numbers when I came to this department, however, my lecture notes are full of letters and symbols like a literature 
Table 1 Instructional objectives and obtained acquisitions regarding to the students

\begin{tabular}{|c|c|c|c|c|c|c|c|c|c|c|}
\hline & \multicolumn{5}{|c|}{ Instructional objectives ${ }^{a}$} & \multicolumn{5}{|c|}{ Obtained acquisitions $^{a}$} \\
\hline & & Procedural flexibility & Conceptual understanding & Abstract thinking & Interdisciplinary relation & Algebraic thinking & Computation & Proving theorems & Using representation & Visualization \\
\hline \multirow[t]{2}{*}{ CAS } & $f$ & 7 & 10 & 4 & 6 & 3 & 5 & 4 & 12 & 11 \\
\hline & $\%$ & 39 & 56 & 22 & 33 & 17 & 28 & 22 & 67 & 61 \\
\hline \multirow[t]{2}{*}{ Traditional } & $f$ & 14 & 3 & 10 & - & 11 & 8 & 8 & - & 2 \\
\hline & $\%$ & 56 & 12 & 40 & - & 44 & 32 & 32 & - & 8 \\
\hline
\end{tabular}

The categories in the table contain the most frequently encountered written answers. Because the students can choose more than one category, total categories exceed $100 \%$ 
student, which shows that for mathematicians, proofs are much more important acquisitions than examples or any special situation.

Students in CAS group: CAS-supported learning process contributed mostly to my skills of interpreting derivative and anti-derivative graphics. I can switch from derivative equations to primitive function graphics easier by using CAS, and I can interpret the meaning of rise and fall in graphics in derivative equations.

\section{Attitudes towards usage of CAS}

Thinking type differences were taken into consideration while attitudes towards the usage of CAS were evaluated within the context of objectives and acquisitions in calculus. For this purpose, the interviews have been conducted with a participant who can represent the teaching environment and has different thinking types. While evaluating reasons of participants about demanding or refusing CAS integration into calculus classrooms, each participant was asked to answer the following question: "What are the roles of CAS support in accomplishing the objectives of the course and carrying on the acquisitions which were gained after a learning period?"

Some participants' (CAS-A, CAS-V and Tra-V) opinions about the usage of CAS are evaluated under the category of "positive but limited". These participants converged on the idea that CAS can be used in calculus, but boundaries should be determined. While CAS-A and CAS-V pointed out that technology support is important for the objective of "conceptual understanding" and "interdisciplinary relation" respectively, a reservation of the participants is the negligence of the abstract nature of mathematics when used with technology.

CAS-A: I am standing with the idea that boundaries of technology support should be well determined. I think technology support will contribute to relational understanding, but CAS is not necessary all the time. First, you should know the concept, have theoretical background and then we can pass on to computer application... I do not find it meaningful to visualize everything, mathematics is abstract, and thinking skills in this aspect should be developed more.

CAS-V: Although, the software (LiveMath) is not useful for proving theorems; I could understand and interpret the definition of integral at numerical and graphical perspectives... Solving real world problems which require interpreting graphical or tabular data is so easy. The software we use encourages me not just for that moment, but to think visually about other problems too.

A common drawback of participants is that the usage of CAS will affect procedural fluency negatively. Participants who evaluated under "positive but limited" categories demanded that the software which mathematical-symbolic language can be used flexibly should take place more frequently in the process, while referring to the acquisitions of the course (Table 2). For instance, Tra-V stated that teaching calculus with the traditional method supports calculation skills more. Although Tra-V did not take place in a 
CAS-supported teaching environment before, he demands CAS integration on the grounds that technology support brings more visual elements to the learning environment.

Tra-V: Teaching the course with computer support and showing graphic during the course brings to a successful conclusion in terms of concretization. For example, it would be better if technologies supporting visual quality were used in slope of secant line which is the interpretation of the derivative as geometrically... Frequently usage of CAS during the calculation process may decrease our procedural capability. This is why CAS support should be limited in the mathematics classroom.

The only participant with a negative attitude about the usage of CAS is Tra-A. This participant stated that the rules and formulas learned in the traditional classroom are recognized and recalled more easily, and formulas can be used more flexibly in related problem situations. On the other hand, it was observed that the opinion of Tra-A was shaped by a perception of mathematicians in society.

Tra-A: In computer-supported environment, student may not be able to develop a basic level of procedural knowledge. What's important is administrating the process and this type of tools wear down this ability over time. I am pleased with traditional content and running of the course. For the most part, I understand lecture notes on the board and at least I can browse through them at home... Mathematicians cannot carry a computation tool which can do differential-integral calculus and perception of mathematicians in society requires doing operations with paper and pencil or mentally.

It is also determined that CAS-V and Tra-A are the two participants who think they obtained more acquisitions according to the teaching environment variable. While CAS-V pointed out that after CAS-supported teaching process their competences of "using representations", and "visualization" have developed; Tra-A pointed out that their competences of "algebraic thinking", "calculation" and"proving theorems" have developed. Additionally, according to the participants with analytical thinking, in order to attain the objectives of the calculus course and retaining acquisitions, CAS-supported contents which do not conceal procedural steps and damage calculating ability should be included in the learning process. However, participants with visual thinking suggested that technologies such as CAS should be used as a means of visualization and concretization in order to form interdisciplinary relation.

Table 2 Impact of CAS-supported teaching on the objectives and acquisitions of the calculus

\begin{tabular}{lllll}
\hline & & Attitude & Objectives $^{a}$ & Acquisitions $^{a}$ \\
\hline Participants & CAS-A & Positive but limited & $(\uparrow)$ Conceptual understanding & $(\leftrightarrow)$ Algebraic thinking \\
& CAS-V & Positive but limited & $(\uparrow)$ Interdisciplinary relation & $(\leftrightarrow)$ Proving theorems \\
& Tra-A & Negative & $(\downarrow)$ Abstract thinking & $(\downarrow)$ Computation \\
& Tra- $V$ & Positive but limited & $(\leftrightarrow)$ Interdisciplinary relation & $(\downarrow)$ Computation \\
\hline
\end{tabular}

a $(\uparrow)$ Positive impact, $(\leftrightarrow)$ Neutral impact, $(\downarrow)$ Negative impact 


\section{Discussion}

The interaction between students and technology are quite important in the process of integration technology into teaching-learning environments (Marshall et al. 2012; Meagher, 2011). Students' expectations and demands on CAS integration in calculus were evaluated in this study. Findings showed that students set different limits on usage of CAS in learning environments. Consequently, while some of the students in the study stating that technologies such as CAS should be used limitedly in learning environments; they tried to explain the reason for this statement by citing the objectives and acquisitions of the course. Some students hold prejudices about the nature of calculus knowledge and technology compatibility in terms of visualization, especially students who are in the traditional group. It was noted that there were similar prejudices in the related literature. In one of these studies Eisenberg and Dreyfus (1991) claimed that most of the visual proofs are not accepted as real mathematical proofs by lecturers and students. However, it is injudicious to think that visualization harms the abstract nature of mathematics. Visualization of a mathematical concept does not mean concretization of it, it means establishing relationships between the analytical and the geometric nature of the concept. Therefore, students are making more effort while managing visual processes and they are able to make higher cognitive acquisitions (Presmeg, 2006). Traditional contents and approaches without visual elements prompt students to rulebased thinking and rote learning (Alcock \& Inglis, 2010). Aims of students in the traditional group regarding the calculus might be affected by the previous learning experiences and/or paradigm of lecturers. Because a great majority of students in the traditional group attributed to the importance of using symbolic language for "procedural skills" and "proving theorems", which explains the reason why they remained distant on technology usage. Giving more attention to the procedural competence in the traditional group can be explained based on the "community of practice" phenomena. For instance, Sofronas et al. (2011) stated that mathematicians trust formal notation language more in the process of proving theorems, interpreting findings, making inferences, and generalization. Besides, Pierce (1999) interprets students' finding traditional environments more reliable as a result of their lack of confidence about technological content knowledge. Similar inferences were obtained in Hung's (2001) research, and he found that lecturers who are not capable of using technology are more likely to choose programs that concentrate on calculation modules (cited in Tokpah, 2008). The fact that less usage of visual elements in the teaching process of the traditional group may have prompted students to use algebraic solutions is another reason why students in the mathematics department remain distant about CAS usage in learning environments is related to epistemological beliefs. It can be concluded from opinions of participants such as "real mathematicians do calculations with paper and pencil" or "nature of mathematics is symbolic, there is no need for visualization" that they are under the influence of lecturers' epistemological beliefs (Muis, 2004).

Another component whose effects on usage of technology in calculus have been researched is thinking type differences. The findings of the study show that it would not be correct to make inferences about demands on CAS usage according to the thinking types; but some inclinations could be appointed if teaching environment and thinking types were considered together. Participants who have the most positive and negative attitudes towards CAS usage are visual participants in the CAS group (CAS- 
V) and analytical participant in traditional group (Tra-A), respectively. CAS might be considered scaffolding tools, which will bring different perspectives with multiple representations and visualization interface (Pierce, 1999). Thus, technology enriches learning environment provides alternative contents for students with different thinking types. In one of the studies that support this inference Sevimli (2013) stated that CAS-supported teaching approaches, provides students an environment which enables students to choose appropriate content based on their cognitive preferences. In this study, especially the participants with visual thinking type stated that they could observe numerical, geometrical and algebraic interpretations of derivative and integral with the support of CAS, explicitly (CAS-V, p. 18). On the other hand, thinking of the technology only as a device of visualization would mean ignoring the other capabilities of technology such as modelling and developing strategies. Therefore, enriching learning environments where technology is used with activities containing real-life problems and cognitive relations can be established can fulfil the expectations of visual students better.

Participants who are analytical thinkers remain more distant to CAS usage than visual participants in calculus, and the fact that acquisitions, which were thought to be accomplished by the end of the course were limited, might have affected the attitudes of analytical participants regarding CAS usage. At this point, analytical participants in the traditional group remain distant to CAS usage on account of the fact that procedural skills might be negatively affected. Tra-A has bias towards a learning environment which he has not experienced before (e.g., the usage of CAS negatively affects calculation skills and conceals the procedural steps). When opinions of the participants were gathered together it was discovered that using instructional technologies which are computer or calculator-based and which do not show intermediate steps to calculations (e.g., works with the result-oriented principle), were perceived as technology integration. In fact, it has been known that analytical thinkers are able use rule-based approaches more flexibly and they rely on algebraic representations more. Hughes-Hallett (1991) stated that for many calculus lecturers and students being competent in calculus are equal to the ability of manipulating symbols and numbers. In another study, Sofronas et al. (2011) determined that after the negotiations with calculus textbook authors and well-known professors in the US, for a great majority of participants, procedural skills are the leading acquisitions of calculus, and the rate of the participants who mention technology support was limited. Based on the related literature and concordantly with the course objectives it can be understood why analytical participants remain distant to mathematics software that conceals procedural steps. However, regarding mathematical software only as an input-output system by analytical participants in the traditional group limits the usage of technology and brings out the opinion that in traditional classrooms doing calculations with paper and pencil is more instructive. Thus, with the opinion of Tra-A "we made this commands meaningful for computers and we make a bid for computers to do this handwork instead of us" confines technology usage to "crosschecking". Analytical participants in the CAS group intend to use technology with the purpose of reducing the burden of operation different from the traditional group. In many studies in the literature, it is pointed out that mathematics software can be used to reduce the time spared for tedious calculations and this time can be used to support conceptual understanding (Harper, 2007; Pierce, 1999; Sevimli, 2013). 
The fact that the syntax of instructional software (LiveMath) which was used in the study is compatible with mathematical notions (typeset math, not computer code) and software's showing the intermediate steps in the calculation process might have explicitly affected the opinions of the participants. Besides, the fact that visual participants pointed out more acquisitions than analytical participants at the end of the CASsupported teaching process may show that analytical thinkers are either not aware of acquisitions such as "using representations" and "visualization" or they do not regard these acquisitions as mathematical qualifications. While visual participants demanded CAS support more than analytical ones because of the fact that they obtained their objectives better, participants in the traditional group generally remained distant from the usage of CAS due to epistemological beliefs related to the abstract nature of the calculus.

\section{Conclusion}

The results of the study showed that students in the traditional group pay more importance to procedural fluency, while students in the CAS group attach more importance to conceptual competencies in terms of instructional objects. In addition to this, it was stated by students that the traditional teaching environment supports procedural fluency, and the CAS-supported teaching environment assists using multiple representations and visualization aspects more. According to the results obtained from the interview findings, visual participants demanded CAS support more than analytical participants, and the relation between objectives and acquisitions are important in attitudes about integrating technology into calculus. In this sense, it was observed that participants who remain distant to the usage of technology (CAS) in the learning process are mainly in the traditional group, or they are mainly analytical thinkers. For participants in this study, epistemological beliefs related to the abstract nature of the calculus and for participants with analytical thinking type confidence on algebraic solutions and the idea of harming of procedural skills are the reasons for the limited usage of CAS.

The main implication of the study is that the objectives of the course and characteristics of the target audience should be taken into consideration while integrating technology in a learning environment. It seems that technology demands and attitudes of participants with different thinking types in the same learning environment or participants with same thinking types of different learning environments may differ. Undoubtedly the results of this study are limited by the self-assessment capacity of the participants. Therefore, asserting that analytical participants in traditional classrooms or visual participants in CAS-supported classrooms can obtain more acquisitions would be wrong. However, the results of the study bring an important projection regarding self-assessments of participants in different teaching environments, and with different instructional characteristics. The aim of this study is not to reach a generalization, but to thoroughly examine the reasons why students need technology. Consequently, interviews were carried out with a limited number of students. However, a new study, which will be conducted with a larger sample can explain how technology demands of students change according to thinking types and department differences. In other candidate studies which could be follow-ups of this study, it is suggested that researchers analyze the opinions of students about technology usage in didactics of 
mathematics with samples, discipline, and data collecting tool diversification. For example, compatibilities and incompatibilities between student expectations about different mathematics classrooms in different educational levels (such secondary, high school and higher education) and capabilities of mathematical software could be examined. Moreover, differences in the students' thinking types and course requirements should be taken into account when designing a technology-enhanced learning environment by lecturers and software developers.

\section{Acknowledgements}

This paper is a revised and extended version of a paper that was presented at 13th International Congress on Mathematical Education (ICME-13) in July 24 - 31, 2016, in Hamburg/Germany.

\section{Authors' contributions}

The author has made substantial contributions to conception and design, analysis and interpretation of data, has been involved in drafting the manuscript and revising it critically and has given final approval of the version to be published. He also read and approved the final manuscript.

\section{Authors' information}

Eyup SEVIMLI, Ph.D., is currently an assistant professor in the Department of Mathematics Education of Gaziosmanpaşa University, Tokat, Turkey. His research interests include advanced mathematical thinking, integration technology into mathematics classroom and representational system in mathematics education. He also has experience in university teaching and textbook design.

\section{Competing interests}

The author declares that he has no competing interests.

Received: 29 April 2016 Accepted: 29 September 2016

Published online: 01 December 2016

\section{References}

Alcock, L., \& Inglis, M. (2010). Visual considerations in the presentation of mathematical proofs. International Journal of Media, Technology and Lifelong Learning, 6, 43-59.

Borromeo-Ferri, R. (2010). On the influence of mathematical thinking styles on learners' modelling behaviour. Journal für Mathematik-Didaktik, 31, 99-118.

Brown, M., \& Steele, C. (2014). MathExplorer: exploring maths for engineering students. Teaching Mathematics and Its Applications, 33, 65-80.

Buteau, C., Marshall, N., Jarvis, D., \& Lavicza, Z. (2010). Integrating Computer Algebra Systems in post-secondary mathematics education: preliminary results of a literature review. International Journal for Technology in Mathematics Education, 17, 57-68.

Cavin, M. (2007). Developing technological pedagogical content knowledge in preservice teachers through microteaching lesson study. Ph.D. thesis. USA: Florida State University.

Chappell, K., \& Kilpatrick, K. (2003). Effects of concept-based instruction on students' conceptual understanding and procedural knowledge of calculus. PRIMUS, 13, 17-37.

Eichler, A., \& Erens, R. (2014). Teachers' beliefs towards teaching calculus. ZDM-The International Journal on Mathematics Education, 46, 647-659.

Eisenberg, T., \& Dreyfus, T. (1991). On the reluctance to visualize in mathematics. Visualization in Teaching and Learning Mathematic (W. Zimmermann \& S. Cunningham eds.). Washington: MAA.

Galindo-Morales, E. (1994). Visualization in the calculus class: Relationship between cognitive style, gender, and use of technology. Ph.D. thesis. USA: Ohio State University.

Haciomeroglu, E., Aspinwall, L., \& Presmeg, N. (2010). Contrasting cases of calculus students' understanding of derivative graphs. Mathematical Thinking and Learning, 12, 152-176.

Harper, L. (2007). The use of Computer Algebra Systems in a procedural algebra course to facilitate a framework for procedural understanding. Ph.D. thesis. USA: Montana State University.

Hughes-Hallett, D. (1991). Visualization and calculus reform. Visualization in Teaching and learning mathematics (W. Zimmermann \& S. Cunningham eds.) (pp. 121-126). Washington: MAA.

Hung, D. (2001). Theories of learning and computer-mediated instructional technology. Education Media International, 38(4),282-286.

Kaput, J. (1992). Technology and mathematics education. Handbook of Research on Mathematics Teaching and Learning (D. Grouws ed.) (pp. 515-556). NY: Macmillan.

Kendal, M. (2002). Teaching and learning introductory differential calculus. Ph.D. thesis. Australia: University of Melbourne.

Lean, G., \& Clements, M. A. (1981). Spatial ability, visual imagery, and mathematical performance. Educational Studies in Mathematics, 12(3), 267-299.

Lincoln, Y., \& Guba, E. (1985). Naturalistic inquiry. Beverly Hills, CA: Sage.

Lowrie, T., \& Kay, R. (2001). Task representation: The relationship between visual and nonvisual solution methods and problem difficulty in elementary school mathematics. Journal of Educational Research, 94, 248-253.

Marshall, N., Buteau, C., Jarvis, D., \& Lavicza, Z. (2012). Do mathematicians integrate computer algebra systems in university teaching? Comparing a literature review to an international survey study. Computers \& Education, 58, 423-434. 
Meagher, M. (2011). Students' relationship to technology and conceptions of mathematics while learning in a Computer Algebra System environment. International Journal for Technology in Mathematics Education, 19, 3-16.

Muis, K. (2004). Personal Epistemology and mathematics: A critical review and synthesis of research. Review of Educational Research, 74, 317-377.

Nabb, K. (2010). CAS as a restructuring tool in mathematics education. Proceedings of the 22nd International Conference on Technology in Collegiate Mathematics. (see http://www.keithnabb.com/yahoo_site_admin/assets/ docs/CAS_As_A_Restructuring_Tool_in_Mathematics_Education.28990404.pdf) [accessed 16 May 2014].

Nishizawa, H., Kimura, K., Ohno, W., \& Yoshioka, T. (2014). Interactive worksheets for connecting symbolic and visual representations of 3D vector equations. Teaching Mathematics and Its Applications, 33, 52-64.

Pierce, R. (1999). Computer Algebra Systems facilitate positive learning strategies. (J. Truran \& K. Truran eds.), Making the Difference. Proceedings of the 22nd Annual Conference of the Mathematics Education Research Group of Australasia. Sydney: MERGA.

Presmeg, N. (1985). The role of visually mediated processes in high school mathematics: A classroom investigation. Ph.D. thesis. UK: University of Cambridge.

Presmeg, N. (2006). Research on visualization in learning and teaching mathematics. In A. Gutierrez (Ed.), Handbook of Research on the Psychology of Mathematics Education: Past, Present and Future. Rotterdam: Sense.

Quesada, A., Richard, L., Wiggins, \& M. (2008). The impact of the graphical approach on students' understanding of the definition of limit. International Journal for Technology in Mathematics Education, 15, 95-102

Rasmussen, C., Marrongelle, K., \& Borba, M. (2014). Research on calculus: what do we know and where do we need to go? ZDM-The International Journal on Mathematics Education, 46, 507-515.

Samuels, J. (2010). The use of technology and visualization in calculus instruction. Ph.D. thesis. USA: Columbia University.

Sevimli, E. (2013). The effect of computer algebra system supported teaching on students' processes of transition of representations in integral with the thinking type differences (English abstract). Ph.D. thesis. Turkey: University of Marmara.

Sofronas, K., De Franco, T., Vinsonhaler, C., Gorgievski, N., Schroeder, L., \& Hamelin, C. (2011). What does it mean for a student to understand the first-year calculus? Perspectives of 24 experts. The Journal of Mathematical Behavior, 30, $131-148$.

Strauss, A., \& Corbin, J. (1998). Basics of qualitative research: Techniques and procedures for developing grounded theory (2nd ed.). Thousand Oaks, CA: Sage.

Suwarsono, S. (1982). Visual imagery in the mathematical thinking of seventh-grade students. Ph.D. thesis. Australia: Monash University.

Swidan, O., \& Yerushalmy, M. (2014). Learning the indefinite integral in a dynamic and interactive technological environment. ZDM-The International Journal on Mathematics Education, 46, 517-531.

Tall, D., Smith, D., \& Piez, C. (2008). Technology and calculus. In M. K. Heid \& G. W. Blume (Eds.), Research on technology and the teaching and learning of mathematics (pp. 207-258). USA: NCTM, Publications.

Tokpah, L. (2008). The effects of Computer Algebra Systems on students' achievement in mathematics. Ph.D. thesis. USA: Kent State University.

Vincent, E., Andrew, S., Lang, D., \& Locke, L. (2010). Teaching calculus with Wolfram|Alpha. International Journal of Mathematical Education in Science and Technology, 41, 1061-1071.

Vlachos, P., \& Kehagias, A. (2000). A Computer Algebra System and a new approach for teaching. Journal of Computer Algebra in Mathematics Education, 7, 87-104.

Wilson, R. (1997). A decade of teaching "reform calculus" has been a disaster, critics charge. The Chronicle of Higher Education, 4, 12-13.

\section{Submit your manuscript to a SpringerOpen ${ }^{\circ}$ journal and benefit from:}

- Convenient online submission

- Rigorous peer review

- Immediate publication on acceptance

- Open access: articles freely available online

- High visibility within the field

- Retaining the copyright to your article

Submit your next manuscript at $>$ springeropen.com 